\title{
Are there Tourists Amongst us? A Participant- Centred Appraisal of an International Competitive Football Tournament in Malta
}

\author{
Damian Spiteri*, Adele Muscat** \\ Corresponding Author: Damian.Spiteri@mcast.edu.mt \\ *Institute of Community Services, MCAST \\ **Institute for Physical Education and Sport, University of Malta
}

\begin{abstract}
In Malta, there is an active history of both governmental and non-governmental organisations who strive to organise a variety of sports activities. Often, participation in sport, particularly among young persons, is seen as a means to enhancing participants' emotional self-regulation, self-esteem, and problem-solving capabilities, although it is also used as a crime-prevention strategy particularly in neighbourhoods which are characterised by crime and anti-social behaviour. This paper explores what football players, their coaches, and other officials who accompanied the young participants in an international football tournament, specifically the Union of European Football Association (UEFA) Under-17 tournament, believe they derived from this tournament. It also explores the manner in which different teams and cultures portray themselves, and the wider social and cultural influences that are believed to have a bearing on their perceptions. The paper is of particular interest to people who operate in the field of youth tourism since it promotes a greater understanding of the outcomes (personal, social, economic, etc.) that both local and foreign players, participating in a football tournament of international importance perceive as outcomes.
\end{abstract}

Keywords: Youth tourism, football, economy, identity, development outcomes.

\section{Introduction}

Participation in sport is seen as a healthy undertaking for youth and the benefits of sport proliferate throughout academic literature (Heaward et al. 2008, Pascarella and Terenzini 1991, 2005; Reisberg 2001). Youth participation in sport, particularly when undertaken is widely portrayed as a way in which people can enhance their emotional self-regulation, self-esteem, and problem-solving capabilities, thereby contributing positively to their physical, mental, and emotional development (Brown 2005). Sport has also been purposely employed as a crime-prevention strategy in neighbourhoods which are characterised by crime and anti-social behaviour (Cameron and MacDougall 2000; Hartmann and Depro 2006; Richardson 2012; Smith and Waddington 2004). From an academic perspective, participation in sport is acknowledged to correlate positively with academic success in college and university settings (Daugherty and Lane 1999; DeBerard et al. 2004). From a neighbourhood and community perspective, sport is also seen as beneficial, not only since residents and community-members may take pride that sports events are organised in their locality, but also, as a result of the revenue that is generated if or when external visitors attend (Kim and Chalip 2004). In the case of youth tournaments, these visitors can include parents, relatives, and friends of the players and other participants, although this list could be widened to include fans, and sometimes, the participants themselves. All are likely to need food and accommodation. They may 
also need to purchase items for daily use, and may buy items such as souvenirs and postcards, or, in a manner not unlike tourists, may tour the area if they are unfamiliar with it. Hinch and Higham (2001: 52) observe that, "for many sport tourists a specific sporting event may function as the primary attraction in a destination, but a cluster of other nuclei (possibilities), found in the surrounding area, may be needed to finalise the decision to travel." Further possible revenue may be generated from the use of sports equipment or, in some cases, from the hire of the venue where the tournament is to be held, or from other ancillary activity associated with the hosting of the event (Allen et al. 2011).

This paper explores what football players, their coaches, and other accompanying officials during an international football tournament, in this case the UEFA Under-17 tournament, believe that they derived from this tournament. All the players were males in the 16-17 age category. The tournament was held in Malta in May 2014. While Malta was not technically a qualifying country for this competition since it was the host country, the Maltese team was allowed to take part. In effect, Malta offered several advantages as a country where the tournament could be held. For many years, now, Malta has served as a tourist destination mainly to Europeans who seek out Malta's central Mediterranean location, its relative proximity to other European countries (where tourists may save holiday time and money by not travelling too far), its cultural and historical artefacts and characteristics, its wide use of the English language, and its favourable climatic conditions.

It is likely that, in choosing Malta as the venue for the tournament, the organisers of the event also considered the country's political stability (and thereby safety of participants), the island's high quality and competitive hotel industry (and thereby quality for money), its easy accessibility since many of the leading European airlines including low-cost airlines fly into and out of the country, and its use of the Euro (thereby offering a certain degree of added convenience). In all probability, most tourists are increasingly looking for cultural experiences during more frequent but shorter holidays, therefore it is likely that Malta's rich history is another plus-point for the island nation's tourism (Chen 2006). As with larger events, the UEFA Under-17 tournament, shared with other sports activities, "the potential to attract non-residents, media, technical personnel, athletes, coaches and other sporting officials" (Kurtzman and Zauhar 2003: 44; Kurtzman and Zauhar 2005), many of whom would travel mainly, if not specifically, to see the event.

The development and implementation of recreational sports programmes and facilities is however, not only of interest, from a touristic stand-point, as it is also associated with an appropriate use of leisure time that fulfils such needs as self-expression and the need for belonging. Although men and women may express these needs differently, it is likely that both these genders participate in competitive games as well as games that are more recreational in nature; namely games in which teams usually allow everyone a chance to play and often compete against personally known or local counterparts (Wankel and Beger 1990). Generally speaking, male sports tend to be seen as having a more competitive nature. This may be associated with the way society is structured, since many sports are associated with male hegemony (Kennedy 2009). Unfortunately, even recent literature dating from the last decade, points out that females tend to be underrepresented in research, not only in sports, but also in science-based subjects (Ceci and Williams 2011; Krishnamurthy et al. 2017; Pape 2019).

Football, in Malta, as elsewhere, is a highly popular sport. (Football is referred to in the US as soccer - the two terms are synonymous). Around 270 million people participate actively in football globally. More than one billion people watched the Football World Cup 
in June 2006 and over 38 million players were registered at national soccer associations in that year (FIFA 2006). The sport was formally introduced to Malta by the British Services who were stationed on the island from 1800 to 1979. The first match was played on the 4th March, 1882, at Marsa. It was played between soldiers of the Garrison and the Royal Engineers. Eventually, Maltese teams were formed and started playing against each other or against the British Services. Floriana FC and St. George's FC are the two oldest Maltese football clubs. The first league competition for Maltese clubs took place in 1910. Malta played its first international match on Sunday 24th February 1957. This inserted the Malta national team in the international arena. In 1959, the Malta Football Association joined FIFA, and, in 1960, it became a member of the European Football Union - UEFA. Maltese clubs started to participate in the UEFA Cup in 1968. In 1981, the National Stadium of Ta' Qali was built, and in 1983 this was assigned to the Malta Football Association for its administration. Today, it is equipped with all modern amenities. At the turn of the century, a new modern spectator stand was constructed at the stadium (Armstrong and Mitchell 2008). Investment in this sport, shows how with the advent of local, regional, national, and international tournaments, even locally, football has become more than simply a sport. It has become an event which people look forward to, and, in supporting a particular team, express local, or sometimes, national sentiments. This is particularly demonstrated by the fact that the UEFA Under-17 tournament is an international tournament. It enables victory to be seen as an expression of national pride. In some cases, it can also be interpreted as consolidating one's own citizenship. This is because players play for the nation, and spectators, who are supporting their national team, are also inherently supporting their nation.

It must not be overlooked however that the UEFA Under-17 championships form part of a chain of events. It is almost as if they are at a particular point of a continuum in the participants' lives. They are only one aspect of a series of previous exposures of the participants to football at schools, outreach programmes, clubs and other places. Sometimes, these may be located in their respective countries, and at other times they may be located abroad. Underlying these different contexts are the aspirations of players to play football and perfect their practice of the sport, particularly if they are aspiring to take up a career as professional footballers. The UEFA championships are thereby constantly subject to the personal involvement of the players, coaches and other related personnel. Exploring this personal involvement is the main focus of this paper.

\section{Methodology}

In order to attain rich, in-depth qualitative data, the authors utilised a purposive and convenience sampling strategy when selecting participants for this study (Patton 2002). Those eligible needed to be selected from players, coaching, medical staff and officials involved in the UEFA U17 finals in May, 2014. They were interviewed face-to-face. The interviews with the officials were held when in their limited free time, during their stay in Malta for the tournaments. It was assumed that their direct exposure to the UEFA finals, and their contributing to them in some way, was also likely to translate into topical data, an aspect of qualitative research that further consolidates its validity (McMillan 2004; Marshall and Rossman 2006). Since, understandably, not all staff could be on-hand to be interviewed due to other commitments, this implied that not all the people, who were targeted originally by the authors, took part in this research undertaking. Despite the restriction in sample size, the authors managed to recruit nine participants of Maltese, Dutch, British and French nationality. Four were players, while five were coaching and UEFA officials. Permission to interview these individuals was granted from UEFA and the 
Malta Football Association (MFA) organising committee prior to the participants' arrival in Malta. The Maltese players were interviewed one week later, at the Malta College of Arts, Science and Technology (MCAST), where both authors were working at the time. The authors also watched some of the matches being played, so as to observe the participants more closely while in action.

Interviews were conducted using individual semi-structured formal interviews which carried the advantage of allowing access to data along pre-selected themes but yet were flexible enough to also take account of the interviewee's perceptions and subjective appreciations of the UEFA championships (Biddle et al. 2001). Unlike completely structured interviews, semi-structured interviews carry the advantage of allowing the interviewer to ask questions in order to obtain clarifications, or to ask for elaboration on the data provided, when necessary (Welman and Kruger 2000). Although using a semi-structured interview schedule implied that certain themes were introduced to the participants during the interviews by the researchers, these were introduced as flexibly as possible, allowing the participants to introduce to the interview any data they considered relevant, and thereby direct the interviewers to explore with them any issues that they brought up. During the analysis, first order themes were identified foremost, then compared and contrasted. Second and third order themes were subsequently identified. Both researchers ensured, first individually, and thereafter together, that all the data had been saturated. This type of cross-checking contributes to a study's validity (Biddle et al. 2001). In so doing, rather than presenting a wide scale appraisal of the influence of sporting events on host societies, this study is more individually inclined. It is aimed at exploring the subjective view-points of the participants and promoting an awareness about their lived experiences. In common with other studies which are based on interviewing a small number of participants, since this offers, "an intensive, holistic description and analysis of a bounded phenomenon such as a program, an institution...or a social unit" (Merriam 1998: xiv), it is thereby contextually bound. Had other coaches, players, or participants been interviewed, or had the same people been interviewed at another stage in life, it is highly likely that the responses given would have been different. This makes it difficult to generalise findings. Having said this, it offers a means to understanding what participating in the UEFA Under-17 championships means to those taking part.

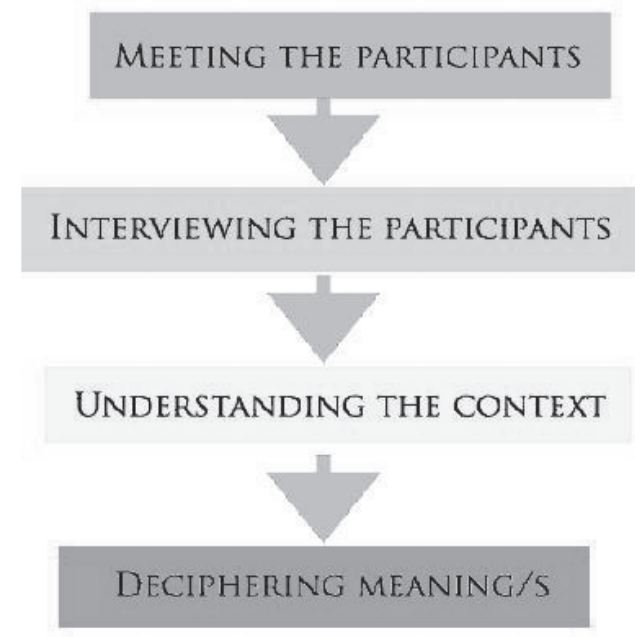

Figure 1: Pathway to understanding the participants 
The authors took their time to reassure the participants about confidentiality in terms of collection of data, recording and presentation of the study. This is because the football environment is generally seen as a characteristically closed environment and one that is sceptical about the presence and/or role of outsiders (Parker 1995). Transcripts were analysed partially using principles of content analysis (Côté et al. 1993; Strauss and Corbin 1998) and partially using principles that were adapted from a grounded theory methodology which aims to build theory, "from the ground" (Goulding 2002: 55), and therefore focuses on participants' reality without introducing previously conceived notions or theories (Glaser and Strauss 1967). In other words, they left the participants free to say their own thing. The choice of this methodology came about after the authors reflected on Holt's (1995) model of sport consumption which is based on the different attitudes that persons may have toward participating in sport. For instance, some players may have identified with their team using rational and emotional behaviour, and may have been far more interested in their own team than in the overall running of the event, and yet may have felt reluctant to talk about it. Others may have integrated the identity of their club with their sense of self, and may have wanted to show their club as superior and better than any other, simply because they believed it was so or because they wanted to believe it was so. They may not have welcomed any challenging of this ideal. Yet, others may have looked at the play factor, noting how enjoyable the experience was for the players taking part and how this contributed to their overall development as footballers and as people. It was thereby a necessary aspect of the study that the participants were made to feel as comfortable as possible when speaking to the researchers about whether these biases and fears were to be minimised.

One of the authors (AM) stayed at the accommodation venue during the tournament days. (She is the sports psychologist assigned to the Maltese U17 team and was on-site to give whatever assistance was necessary to the team). This enabled her to be more visible to the participants and to thereby engage their trust. The other author (DS) was introduced to the participants by AM. All interviews were conducted by the authors together. The interviews with players, coaches, medical staff and officials were conducted at the accommodation venue, which was a hotel in Mellieha, located to the north of Malta, and about 30 minutes by road from the Ta' Qali stadium, where both the event, and any run-up practice sessions were taking place. The presence of both researchers during the interviews evidenced that they employed a team effort throughout this study. In essence, unlike in certain other studies, peer triangulation did not only take place when the first interview guide was put together, and eventually was further refined until both researchers were content with the final version, as well as when the interviews were analysed - something which could be readily evidenced by the amount of discussion which the authors generated about the data. Each interview was conducted in English and lasted between 20 and 40 minutes and the data given was recorded electronically. Even though the transcribing of interviews may be problematic, since it is likely that certain non-verbal aspects of the interview will be overlooked, so as to ensure that the transcripts were as accurate as possible, they were transcribed as soon as possible after the interview. Since different people have different aptitudes and ways of transcribing, it was decided that only one of the authors (AM) transcribe the texts. On completion of this task, the transcripts were read a number of times over by both authors. This was done so as to ensure that the requisite familiarity with them was established prior to research analysis. Ensuring that the text is well understood enables as close a representation as possible of what took place during data collection to come about (Roulston, deMarrais and Lweis 2003). It also profits from the diversity of outlook of the researchers, since although both authors specialised in the social sciences, DS came from a sociology background and AM from a psychology background. Further complementing this diversity was that DS is male, and AM is female. 


\section{Participating In a Youth Football Tournament: Its Implications}

The players, their coaches, and the other officials who served as participants in this study shared in the common view-point that specialising in playing football needs to be part of a broad overall education. This is not only because only few would eventually become professional players, thereby would need to look for employment elsewhere, and needing other skills in the process. Also, because a broader education serves to give players a more informed understanding of the world around them which further enhances how they understand and perceived the game. While, on the one hand, participating in the UEFA Under-17 tournament was in a way seen as a manner of expressing loyalty to one's own country since players were playing for a national team; on the other hand, it was seen as an opening which would help them build their career within the sport, and thereby was viewed as something deeply personal and competitive.

The young age of the participants was also an important aspect of this dynamic since the years when players become 16 and grow to 17, could prove to be an important time for young footballers, particularly those who are more talented, and who may attract the attention of clubs who could offer them employment. This translated into a responsibility for the coaches present to empower the young persons in their charge, and to nurture and develop their talents (McShane 2002). Failing this, the young players were in danger of ending up ill-prepared to make the transition to the senior level of football playing, and were likely to eventually lose sight of possibilities of playing professionally. Although the acquisition of the correct techniques, skills, and tactical knowledge, ideally needs to be accompanied by strength, endurance, stamina, speed, and flexibility, and this is readily comprehended by most players who train hard in order to achieve them, in this study, the coaches emphasised the need for another dimension of the sport in order to consolidate this effectively. This was for players to have the correct psychological acumen to deal with success and failure, as without it they would be unable to deal with the emotional challenges that the game presents. They believed that it was only by looking at the players in their charge as individuals that they could take into account the various stages of their physical, psychological, and social development, and adapt to them accordingly, thereby evolving the coach-player relationship constructively. Haugen et al. (2019) point out a further avenue of sports coaching that they advise practitioners to keep in mind, that is, of constantly striving to uncover the underlying mechanisms for success factors and methods that athletes manifest, and to thereby be better equipped to reinforce the athletes' resiliency and determination to reach pre-set goals.

Judging by the researchers' ongoing observations throughout the tournament, personnel involved directly with the youths, including the coaches, played the role of mentors, while engaged in practise sessions. On observations during the actual tournament, the researchers observed that the coaches appeared to get caught up in the heat of the game, seemingly more focused on engaging the players to use strategies to win the match, rather than mentoring on the personal development of any of the players per se. Too much emphasis on winning has its particular down-side, however, as does cheating and un-sportsmanship behaviour, which may then set in, as the rules of the game may possibly come to be increasingly ignored (Miller, Roberts and Ommundsen 2003). In order to achieve higher levels of coaching efficiency, it may be necessary for coaches to examine their own underlying motives regarding why it is so important for them to win at all costs, if such is the case. Villalon and Martin (2020) advocate sport psychology education and also recommend frequent contact between coaches and sport psychology practitioners, 
in order for coaches to acquire more accurate self-awareness. Compounding this issue is the fact that youth football in general seems to be characterised by a winning is important mentality, no matter the age of the players (McShane 2002).

The UEFA Under-17 Tournament can be easily classified as an elite youth football tournament since it is only young players who have made the grade who take part. Having made it to a leading tournament, it is highly possible that some players suffer burn-out, either due to over-training (which, in turn, may be associated with poor coaching), or due to their inability to handle the stress associated with forming part of a team that expects a good standard of football from each player in the team participating in the tournament, and whereby each player expects a similar high standard from their peers. If the desire to achieve is not matched by efforts towards personal development, this is likely to result in failure and thereby contribute to the risk of burnout as the targets that are set are likely to be physically and emotionally unreachable to the individual concerned (Hill et al. 2007).

An integral part of a person's development as a footballer is resilience. Personality disposition is central to a young player's choice of whether to continue participating, although this may also be influenced by many motives, including conflicts of interests, dislike of the coach, loss of motivation, or even over-bearing perfectionism (Smith and Bar-Eli 2007). Even if the players display a seemingly natural ability to become professional football players, without the correct support, it is likely that their enthusiasm will be seriously dampened (Hoare and Warr 2000). Poucher et al. (2019) also caution that mental health issues can prevail across all sports, and observe how there can be various contextual influences impinging on athletes' lives. These include disorder prevalence, barriers to support seeking, and psychiatric conditions.

Football requires the mastery of different activities including walking, running, sprinting, jogging and jumping. It also demands various kicking techniques, turning, jumping, and a degree of contact between the players. It also requires ball control (Brophy et al. 2007). This needs to be viewed in terms of a gradual evolution of physical and emotional growth during adolescence, which occurs between the ages of 10 and 22 in males (Malina, Bouchard and Bar-Or 2004); keeping in mind that maturation relates to the progressive achievement of adult status through pubertal development (Baxter-Jones 2008). Of course, developmental processes are non-linear and life-events that take place in one's teenage years may also influence how one plays (Abbott et al. 2005).

Within the context of the UEFA Under-17 championships, although the participants are roughly of the same chronological age, this does not necessarily infer that they are equally able to maintain or improve their performance. So much so, that the term trainability (Malina, Bouchard, and Bar-Or 2004) is sometimes used in the literature to describe how able individuals or groups are to respond to training and to further develop their skills and dispositions. Also, even though two players may be of the same age, when annual age groups are used, as is the case with the UEFA Under-17 championships, this infers that a player born in January is almost one year older than a teammate born in December, this possibly signifying a difference in maturation and experience, particularly when speaking about teenagers.

As is to be seen in the following section, the UEFA Under-17 tournaments that were held in Malta are thereby far from a homogenous affair. Rather they depend on a complex interaction between a number of factors, including what different individuals can do and are willing to do (for the practice of the game), the investment in the sport (for the 
promotion of the game), and last, but by far not least, the ability of those involved in planning the game and playing the game to enjoy it (for the perpetuation of the game). The need to develop and constantly re-develop optimal performance strategies needs to be thereby seen as optimally operative within the light of a further need for the players taking part to feel of value to others and for others to feel of value to them.

\section{Results}

A common theme that ran through all the interviews for all the participants was that everyone who was taking part was there to win. As one of the coaches said, "I think all the teams are expecting to win, they want to win. Certainly the qualifying ones do." However, another of the coaches explained the rationale underlying why the focus on winning is important, claiming that the higher up one goes in qualifying to the finals, the greater the satisfaction derived. He said that:

The nicest part of all of this is that the competition is strong... of course it's always good a big event for the players. We qualified through the qualification rounds and this is the final tournament.... The final round is always a special event especially when you come through now to the semi-finals, it becomes more special.

Unpacking the notion of what a desire to win means for the participants thereby points to the fact that it does not seem to be constituted of a striving, to win at all costs. Rather, it seems to relate to the acquisition of what can be called a merited win or a deserved win. This was summarised by one of the Maltese players, when he said, "the important thing is that we do the best we can, we would like to win, but even if we do not win, we do not want to give the opposing team an easy win."

This desire to face good quality competition not only shows the importance of developing a professional outlook in football but also shows the importance that needs to be attributed, by players to developing self-efficacy, or, in other words, the belief that they can successfully carry out train for, and master, the skills to obtain certain goals (Bandura 1997), This ability to develop self-efficacy is linked to the activity of coaches who need to maintain young players' motivational levels, if they are to persist in their efforts on a long-term basis. It is only if young people enjoy practising their sport, that they will engage in self-determined forms of behavioural regulation (Ryan and Deci 2017) and maintain physical activity behaviours. Enthusiasm is as important as perseverance in effective sports training (Ekkekakis et al. 2020; Ekkekakis, Hargreaves, and Parfitt 2013). This research has shown the importance of fostering this enthusiasm clearly. It has shown that unless youth football players are willing to expend maximal efforts to improve and sustain their efforts at participating in football playing, and on improving on their performance in the sport, it is unlikely that they would attain optimal performance levels and/or to retain them (see also research by Ford et al. 2009).

These maximal efforts are driven by a player's determination, perseverance and selfefficacy, all of which derive from life, both on and off the pitch. A teenage player's likelihood for success is thereby dependent on such factors as physical maturation, psychological maturation, and also other related aspects of maturation such as the ability to make friends with others and the ability to enjoy oneself away from the world of football, all of which have an impact on the person's life, particularly if viewed holistically. 


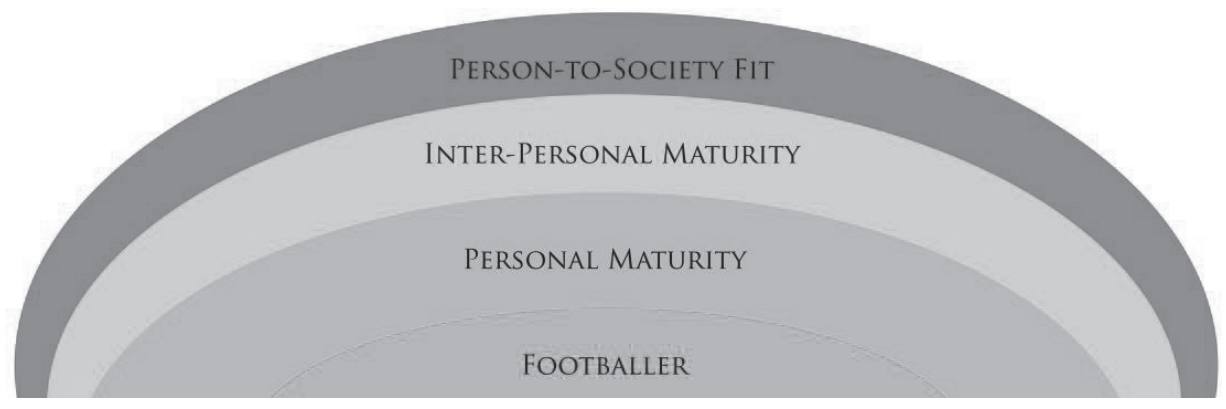

Figure 2: Holistic development of the football player

Simonton (2001) notes that the more well-rounded a player's development is, the greater the player's chances are of being selected for youth academy or representation teams. As one of the coaches pointed out, football is not necessarily linked to academic success, and while there is no reason why it should not be, the two are not intertwined. He said:

We believe that we know what makes a better football player... if you lie in bed all day and attend for one training session and a game, you are not likely to get far. You would be better off if you develop yourself and you develop mentally, physically and emotionally .... of course every player is different so if a player hates school, you cannot force him to attend. You must trust him to find his own way to the top. Other players may combine school with training, using subjects that help them to become a professional football player like nutrition...but much depends on them.

Players also require support from significant others and most may turn to their parents for support. However, at times, parents may not have the required skills and knowledge to support them and thus, professionals from within the club; coaches, sport psychologists, or other support staff may be crucial in the development of young players (Muscat 2017).

Naturally, as one of the players pointed out, in one's understanding of football, we must not leave out the enjoyment of the spectators when the game is finally played out. He noted that "spectators enjoy a good game, a game which offers them a certain element of uncertainty, where it is difficult to predict who will win, and that keeps them slightly on edge till the end." The engagement of spectators was also particularly commented upon by the French official who insisted, that what was important was not only technique but also a demonstration of talent with which spectators can identify. He said:

In my opinion, French football is mainly based on technique, on ball control, on being able to dribble effectively, on being able to do everything the opposing team can do better than they do, a lot has to do with the player's frame of mind. However, the spectators also want to see style, they want to see the right attitude, lots of practical play, and they want to see [the] physical side of football clearly drawn out. It is therefore important to balance, by giving the spectators what they want and yet not losing the attitude toward the game that the French have. 
The Maltese players, on the other hand, focused more on what they could offer noting that the foreign teams have far more experience in their competitive leagues and the international matches they play. They said:

In a way, this plays a very integral part in them being superior, they qualified because of their merit, we qualified because we are hosts. However, this does not mean that we should not play our best, we need to do this, if not for ourselves, for Malta; and if not for Malta, for the people who are watching us.

The enjoyment of the spectators is thereby associated with talent both by the players and the coaches. This is a complex affair since talent is both a multidimensional attribute and a multidimensional process. It is comprised of different components, such as the physical and cognitive aspects of our lived experiences; each having their own rate of development. All players can all be developing differently in any one of these component areas, even though for talent to emerge in a particular area rather than another, some components may be more essential than others (Simonton 2001). This implies that early indicators of talent may be equally discernible to both the coaches and other UEFA staff and to spectators, particularly those who are knowledgeable of football, and who may exert influence on clubs through such means as sponsorship, and so on. This, in turn, can translate into greater opportunities for promising players to migrate to other teams where their development will be further enhanced (Muscat 2017). Within the ambit of the Maltese team, various Maltese players have joined teams abroad, including Michael Mifsud, who played for Coventry; and Andre Schembri who is currently playing at FSV Frankfurt. One of the physiotherapists of the England team explained that in football such migrations are fairly commonplace. He explained how, in his team:

We have, at any one time, about 12 or 13 players on loan. I look after those players as well...mentor those players... I go and watch them play on Saturdays. We have some at Birmingham, Brighton, all over the place. We have one at Valladotta so I go over there and speak a bit of Spanish. We have a lad in Antwerp, a lad in Holland so I go over there to watch those lads play. So I find that very interesting, and also looking at those players going out of their natural environment is interesting. We see that all the time because we send players to different countries regularly. The lad in Valladotta, is from Chile actually, Santiago so I go over there, and he is alone of course, there is no family there, he is only 19, so, to me it seems so odd. Likewise, in Malta, foreign coaches have also come to Malta. The Dutch personnel pointed out ...Andre Paus, Valletta FC manager last year...so we know that name from Holland ...before he came here he was coaching a third level club in Holland.

However, Maltese footballers who have moved overseas have at times found numerous challenges and returned back to the island. Such challenges included: difficulty in adapting to the new culture, learning a new language, to making new friends, doing chores on their own (such as cooking and cleaning), and adapting within the team since the environment within a professional football team may be highly pressurised. The sheltered Maltese upbringing has been found to hinder Maltese footballers from achieving success overseas (Muscat 2017).

In youth football, the desire to win a match, as stated above, was mentioned regularly and featured consistently throughout both the players' interviews and those of the personnel accompanying them. It is thereby the subject of a number of constituent parameters, including emotional self-regulation, providing effective competition, selfefficacy, motivation levels, and taking an active part in one's own personal and physical 
development. This alongside a desire to be noticed by competent personnel who could then direct them toward more senior levels of football, points out to a consciousness that the players are in a stage of development, something that is consistent with their young age, and their looking ahead for opportunities to further their careers in football. However, as the physiotherapist from the England team cautioned, no matter how prestigious the UEFA Under-17 tournament is, and no matter how much preparation went into it:

The sad fact of the matter is that players who play at international level statistically do not make it as top players anyway. If player A, B or C does well in this tournament (the UEFA Under-17 tournament), scores some goals, will he raise his stock? I would say not. There are clubs involved, three Chelsea players, a lad from Fulham who is a top player already ... are their clubs looking at them, judging them? No, I don't think they are. This is what it is. We're on television, scoring a couple of goals... the clubs have their value of that player already. Also, we have a player from Manchester United.. Are the Under-18s' managers looking across, checking how he does? No. I will speak to them at some point and tell them how he did but no, they are not judging his performance on this. This is international football, three or four games, so no, I don't think it is a big stepping stone. It's what you do every day that counts.

This implies that if the players do not necessarily make it to the top level, rather than simply focusing on established concepts of performance, it may be more beneficial for athletes if notions of athlete career excellence were to be introduced (Stambulova 2020). Athlete career excellence refers to an athlete's ability to sustain a healthy, successful, and long-lasting career in sport and life. This implies that a recognition that participating in sport can be seen as a journey where one constantly develops oneself as one practices one's sport is called for.

Having said this, sport tourism and events associated with sport tourism are coming to be seen as an increasingly viable niche market, internationally. This is because such occurrences are seen as backing up efforts at increasing tourism and thereby leave a positive economic impact on host countries (Fredline and Faulkner 2002). Although, in certain instances, economic gain must be measured against the impact on social and cultural considerations of the host country, and at times, its influence on environmental aspects; as can be readily judged by the recent protests to the hosting of the World Cup in Brazil, where protestors took to the streets so as to bring to the government's attention their view that the country's financial resources would be better off spent elsewhere; the UEFA Under-17 tournament did not provoke any negative responses. This is partially because they were to use football grounds that were already set up for the purpose, and therefore, the hosting of the games did not provoke ecological or environmental concerns. Added to this, whereas the World Cup was largely driven by the needs of government to justify the staging of special events based on its economic contribution to the Brazilian economy, in Malta, the matches were a relatively low-profile affair. Although seen as a viable avenue to attract a certain amount of tourism, this was kept in line with the scale and nature of the event. From the point of view of the coaches, however, there appeared to be consensus among them, that the players' expectations were all to do with football. They explained that they wanted the hotel to be comfortable and the food to be good, but what they ultimately wanted was to not let their country down. The French official used the expression, "the proof the pudding is in the eating" to explain how if the French team were present and were to persuade the French people they were a good team, made up of good players, then the only way they could do this was by putting all they could into the match, and ideally winning. The England team on the other hand, said 
that winning was the ideal. The official explained that:

Because there is a lot of criticism in England on footballers and stuff... so even if we've got to the semi-finals, and we say that's OK, we're still being faced with that kind of almost... devil don't care attitude... win it... it is not enough to say 57 teams started, we got to the last four. To the public out there, Britain must come first. Even if maybe the lads think, well, we've done well, the attitude out there is come on, win the tournament.

This shows that spectators' expectations might conflict with those of at least some of the players who insist, for instance (see above), on having healthy competition and who associate satisfaction with winning when confronting this type of competition when playing football. Saying this, it is hard to generalise about what spectators may desire. Spectator outlook on youth football merits further study.

What this study does show, however, is that developing a sound and acceptable sport tourism event practice is also subject to a number of parameters including accessibility to the event and the correct infrastructural and management structures being in place to support it. It is also, however, subject to the outlook of the players and what it means to them to compete in high level international tournaments. This subjective aspect of playing football is sadly omitted in certain studies on tourism related events management. A holistic plan, which takes into consideration the players' development issues and personal desires and aspirations, while at the same time, being focused both on the inputs of interests of those directly involved in the running of the games and on those who serve as spectators, are key to strengthening and contributing to the sport tourism industry in Malta and elsewhere. This is because it will enable all sectors to better understand the game and hence profit from the mutual benefits of sport tourism development. 


\section{References}

Abbott, A., Button, C., Pepping, G. J. and Collins, D. 2005. 'Unnatural selection: Talent identification and development in sport', Non-linear dynamics Psychology and Life Sciences, 9, 61-81.

Allen, J., O`Toole, W., Harris, R. and McDonnell, I. 2011. Festival \& special event management. John Wiley \& Sons (Australia).

Armstrong, G. and Mitchell,J.P. 2008. Global and local football: Politics and Europeanisation on the fringes of the EU. Routledge (New York).

Bandura, A. 1997. Self-efficacy: The exercise of control. Freeman (New York).

Biddle, S.J.H., Markland, D., Gilbourne, D., Chatzisarantis, N.L.D. and Sparkes, A.C. 2001. 'Research methods in sport and exercise psychology: Quantitative and qualitative issues', Journal of Sports Sciences, 19(10), 777-809.

Brophy, R.H., Backus, S.I., Pansy, B.S., Lyman, S. and Williams, R.J. 2007. 'Lower extremity muscle activation and alignment during the soccer instep and side-foot kicks', Journal of Orthopaedic and Sports Physical Therapy, 37(5), 260-268.

Brown, S. A. 2005. 'Measuring perceived benefits and perceived barriers for physical activity', American Journal of Health Behavior, 29(2), 107-116.

Cameron M. and MacDougall, C. 2000. 'Crime prevention through sport and physical activity', Trends \& Issues in Crime and Criminal Justice, 165. Australian Institute of Criminology (Canberra).

Ceci, S.J. and Williams, W.M. 2011. 'Understanding current causes of women's underrepresentation in science', Proceedings of the National Academy of Sciences, 108(8), 3157-3162. DOI:10.1073/pnas.1014871108.

Chen, R. 2006. 'Islands in Europe: Development of island tourism multi-dimensional model (ITMDM)', Sustainable Development, 14(2), 104-114.

Côté, J., Salmela, J. H., Baria, A. and Russell, S. J. 1993. ‘Organizing and interpreting unstructured qualitative data', Sport Psychologist, 7(2), 127-137.

Daugherty, T. K. and Lane, E.J. 1999. 'A longitudinal study of academic and social predictors of college attrition', Social Behavior and Personality, 27(4), 355-362.

DeBerard, M. S., Spielmans, G. I. and Julka, D. C. 2004. 'Predictors of academic achievement and retention among college freshmen: A longitudinal study', College Student Journal, 38(1), 66-80.

Ekkekakis, P., Hargreaves, E. A. and Parfitt, G. 2013. 'Envisioning the next fifty years of research on the exercise-affect relationship', Psychology of Sport and Exercise, 14, 751758. DOI:10.1016/j.psychsport.2013.04.007. 
Ekkekakis, P., Hartman, M. E. and Ladwig, M.A. 2020. Affective responses to exercise. In G. Tenenbaum and R. C. Eklund (eds.), Hand-book of sport psychology. (4th ed.). Wiley (New York), 233-253.

FIFA. 2006. Big Count 2006: 270 million people active in football. Available at: https://resources.fifa.com/image/upload/big-count-estadisticas-520058. pdf?cloudid=mzid0qmguixkcmruvema (accessed 04 November 2020).

Fredline, E. and Faulkner, B. 2002. 'Variations in residents' reactions to major motorsport events: Why residents perceive the impacts of event differently', Event Management, $7(2)$, 115-126.

Glaser, B. and Strauss, A. 1967. The discovery of grounded theory. Aldine (Chicago).

Goulding, C. 2002. Grounded theory: A practical guide for management, business and market researchers. SAGE Publications (London).

Hartmann, D. and Depro, B. 2006. 'Rethinking sports-based community crime prevention. A preliminary analysis of the relationship between midnight basketball and urban crime rates', Journal of Sport and Social Issues, 30(2), 180-196.

Haugen, T., Seiler, S., Sandbakk, $\varnothing$. and Tønnessen, E. 2019. 'The training and development of elite sprint performance: An integration of scientific and best practice literature', Sports Med Open. 5(44). PMID: 31754845 DOI:10.1186/s40798-019-0221-0.

Heaward, A., Ryan, P.A. and Suckling, S. 2008. Closing the gap - Innovation and sustainability in addressing social exclusion through sport. In E. Berg, J. Barry, P. Saiala,

J. Chandler (eds.), Dilemmas of identity, new public management, and governance: Research report. Luleå University, Department of Human Works Science, Division of Social Work (Luleå), 35-41.

Hinch, T.D. and Higham, J.E.S. 2001. 'Sport tourism - A framework for research', International Journal of Tourism Research, 3, 45-58.

Hill, A. P., Hall, H. K., Appleton, P. R. and Kozub, S. A. 2008. 'Perfectionism and burnout in junior elite soccer players: The mediating influence of unconditional self-acceptance', Psychology of Sport and Exercise, 9, 630-644.

Hoare, D. G. and Warr, C. R. 2000. Talent identification and women's soccer: An Australian experience', Journal of Sport Science, 18, 751-758.

Holt, D. 1995. 'How consumers consume: A typology of consumption practises', Journal of Consumer Research, 22, 1-16.

Kennedy, C. 2009. 'The glass ceiling on the playing fields report card III', Gender Issues. 26(3-4), 238-246.

Kim, N. and Chalip, L. 2004. 'Why travel to the FIFA World Cup? Effects of motives, background, interest and constraints', Tourism Management, 25(6), 695-707. 
Krishnamurthy, M., Liao, S., Deveaux, M. and Dalecki, M. 2017. 'The underrepresentation of women in prestigious ethics journals', Hypatia, 32(4), 928-939. DOI:10.1111/hypa.12351.

Kurtzman, J. and Zauhar, J. 2003. 'A wave in time: The sport tourism phenomenon', Journal of Sport Tourism, 8(1), 35-47.

Kurtzman, J. and Zauhar, J. 2005. 'Sport tourism consumer motivation', Journal of Sport Tourism, 10(1), 21-31.

McMillan, J. 2004. Educational Research: Fundamentals for the consumer. Pearson Education (Massachusetts).

McShane, K. 2002. Coaching youth soccer: The European model. McFarland \& Co. (North Carolina).

Malina, R.M., Bouchard, C. and Bar-Or, O. 2004. Growth, maturation and physical activity (2nd ed.). Human Kinetics (Illinois).

Marshall, C. and Rossman, G. 2006. Designing qualitative research. SAGE Publications (California).

Merriam, S. B. 1988. Case study research in education: A qualitative approach. Josey-Bass Publishers (California).

Miller, B. W., Roberts, G. C. and Ommundsen, Y. 2003. 'Effect of motivational climate on sportspersonship among competitive youth male and female football players', Scandinavian Journal of Medicine and Science in Sports, 14, 193-202.

Muscat, A. 2017. Action Research: Preparing Maltese football players for migratory based transitions, PhD dissertation. John Moores University (Liverpool). Available at: http:// researchonline.ljmu.ac.uk/id/eprint/7141/ (accessed 14 October 2020).

Pape, M. 2019. 'Gender segregation and trajectories of organizational change: The underrepresentation of women in sports leadership', Gender \& Society, 34(1), 81-105. DOI:10.1177/0891243219867914.

Parker, A. 1995. 'Great expectations: Grimness or glamour? The football apprentice in the 1990s', The Sports Historian, 15, 107-126.

Pascarella, E. and Terenzini, P. 1991. How college affects students: Findings and insights from twenty years of research. Jossey-Bass (San Francisco).

Pascarella, E. T. and Terenzini, P. T. 2005. How college affects students: $A$ third decade of research. Jossey-Bass (San Francisco).

Patton, M. (2002). Qualitative research and evaluation methods. (3rd ed.). SAGE Publications (California).

Poucher, Z.A., Katherine A., Tamminen, A., Kerr, G. and Cairney, J. 2019. 'A commentary on mental health research in elite sport', Journal of Applied Sport Psychology. DOI: 10.1080/10413200.2019.1668496. 
Reisberg, L. 2001. 'Colleges replace drab gyms with sleek, playful facilities', Chronicle of Higher Education, 47(22), A38.

Richardson, J.B.,Jr. 2012. 'Beyond the playing field: Coaches as social capital for inner-city adolescent African-American males', Journal of African American Studies, 16(2),171-194.

Roulston, K., deMarrais, K. and Lweis, J. 2003. 'Learning to interview in the social sciences, Qualitative Inquiry, 9(4), 643-668.

Ryan, R. M. and Deci, E.L. 2017. Self-determination theory: Basic psychological needs in motivation, development, and wellness. Guilford Press (New York).

Simonton, D. K. 2001. 'Talent development as a multidimensional, multiplicative, and dynamic process', Current Directions in Psychological Science, 10, 39-43.

Smith, A. and Waddington, I. 2004. 'Using 'sport in the community schemes' to tackle crime and drug use among young people: Some policy issues and problems', European Physical Education Review, 10(3), 279-298.

Smith, D. and Bar-Eli, M. 2007. Essential readings in sport and exercise psychology. Human kinetics (Illinois).

Stambulova, N. 2020. Athletes' careers and transitions. In J. Williams and V. Krane (eds.) Applied sport psychology: Personal growth to peak performance. (8th ed.). McGraw-Hill (New York), 519-541.

Stambulova, N. 2020. Athlete career excellence. In L-E. Uneståhl (ed.) Proceedings of the VIII world congress on mind training for excellence in sport and life. Buena Vida Publications (Stockholm), 119-122.

Strauss, A. and Corbin, J. 1990. Basics of qualitative research: Grounded theory procedures and techniques. SAGE Publications (California).

Villalon, C.A. and Scott, B. M. 2020. 'High School coaches' coaching efficacy: Relationship with sport psychology exposure and gender factors' Journal of Applied Sport Psychology, 32(1), 64-80, DOI: 10.1080/10413200.2018.1549620.

Wankel, L. M. and Berger, B. G. 1990. 'The psychological and social benefits of sport and physical activity', Journal of Leisure Research, 22(2), 167-182.

Welman, J.C. and Kruger, S.J. 2000. Research methodology (2nd ed.). Oxford University Press (Cape Town). 